\title{
The Power of Knowledge, Responses to Change, and the Gymnastics of Causation
}

\author{
Michael A. Ashby • Bronwen Morrell
}

Published online: 5 April 2018

C) Journal of Bioethical Inquiry Pty Ltd. 2018

Keywords Knowledge - Causation · Disclosure - End of life $\cdot$ Social change $\cdot$ Technology

This issues explores, inter alia, and in its usual diversity, themes of disclosure, knowledge, response to change, and death causation. We have nine Original Research articles, five Critical Perspectives, one Critical Response, and one Book Review, as well as two Guest Editorials, and the usual Recent Developments. Amongst the Original Research and Critical Perspectives articles we have authors from Argentina, Australia, China, Italy, Jordan, The Netherlands, the United Kingdom, and the United States.

The articles run across clinical ethics, research ethics, and law and address participation in research (Zhang, Huang, and Chen 2018; Tamariz et al. 2018), conflicts of interest (Jacmon 2018), knowledge production (Soofi 2018), academic misconduct (Penders 2018), assisted reproduction (Lima 2018; Shahvisi 2018; Smith and TaylorSands 2018), predictive genetic testing (Manzini and Vears

M. A. Ashby ( $\square)$

Royal Hobart Hospital, Tasmanian Health Service, and School of Medicine, Faculty of Health Sciences, University of Tasmania, Hobart, TAS 7000, Australia

e-mail: michael.ashby@ths.tas.gov.au

B. Morrell

Sydney Health Ethics, Sydney School of Public Health, University of Sydney, Sydney, Australia
2018), family-centred care (Borgan et al. 2018), assisted dying (Richards and Coggon 2018; Duckett 2018), vaccination for drugs of dependence (Carfora et al. 2018), asylum seekers (Essex and Isaacs 2018), and models of clinical decision-making (Parker et al. 2018). They raise issues relating to a number of different vulnerable populations including research participants (Zhang, Huang, and Chen 2018; Jacmon 2018; Tamariz et al. 2018), children (present and future)(Lima 2018; Manzini and Vears 2018; Shahvisi 2018; Smith and Taylor-Sands 2018), racial and ethnic minorities (Tamariz et al. 2018), illicit drug users (Carfora et al. 2018), asylum seekers (Essex and Isaacs 2018), and patients who have run out of treatment options (Soofi 2018).

David Shaw (2018), a member of our Editorial Board, wheels out the trolley problem in a fictitious ethics committee deliberation on thought experiments. The thought finds a thinker, and then the horrified committee "thought polices" itself because the thought cannot be held or even contemplated. So in a sense, the committee destroys its own conversation by being unable to have it. Bryan Magee (1997), in his wonderful philosophical memoir Confessions of a Philosopher shares his experience of post-war Oxford language philosophy and logical positivism as a straightjacket that he felt stifled enquiry and curiosity, by making it hard to say anything without being shot down in flames. Queen Elizabeth I famously said she had "no desire to make windows into men's souls." So do we dare give voice to dangerous thoughts? Or are they hidden or unconsciously present in the room, to do their work in unspoken 
ways? Are ethics committees so scared of their own thoughts and the taboos of the day to say what is really going on? A civil society, and the agreed fundamental values the field of bioethics, require defence at all times, but at what point is our conversation self-censored to the point of self-defeat - a conversation impoverished by its own rules and norms? We hope this piece, in its wry humour, will provoke thought and honour thought's freedom. And maybe our next editorial can look at the role of humour in bioethics!

Much of modern public life is preoccupied with secrets and lies: the quest for truth and information, mostly from the big power bases of the world: governments and major corporations. These "big others" own and finance much for the world's science and technology, and hence these matters are of central interest to bioethics. At a time when information can be more rapidly and widely transmitted than ever before in human history, it is noticeable that, as observed previously in this column, veracity and trust are such fragile commodities and the source of so much angst and scrutiny. Some degree of confidentiality is needed for good government and governance, and of course privacy of citizens is a fundamental right, but where are the boundaries? When the truth is given "economically" or not at all, or when even so-called "fake news" is promulgated, who or what is being protected, to what end, and who knows? Most importantly in bioethics, how is the individual person accorded the respect of knowing what is known about them or the truth of the situation or procedure they are confronted with? Two broad and related themes that emerge in this issue are disclosure practices and the nature of information and knowledge, how it is used and disseminated, and what is hidden, and why.

Disclosure practices are examined in several contexts. Lima (2018), for example, discusses disclosure of genetic origins to donor-conceived children and concludes that knowing about donor conception significantly contributes towards the development of a narrative identity. Jacmon (2018) considers the adequacy of disclosure as a mechanism for dealing with conflicts of interest in human research and argues that relying entirely on disclosure as a solution to the problem of conflict of interest leaves research participants in a vulnerable position. Borgan et al. (2018) use empirical data to discuss the ethics of disclosure in a clinical context - in particular, direct disclosure versus disclosure to family members of a diagnosis of serious illness in conservative societies such as Jordan.
All raise questions about whether and how "knowledge" and "information" empower us.

Many of the articles in this issue also consider aspects of knowledge and information-what it is, how it should be created and used, what responsibilities come with knowledge, and how it is understood by those to whom it is transmitted. In the context of knowledge creation, Soofi (2018) discusses Mode 2 knowledge production, such as participatory and participant-led research, and its application in the medical research context. Penders (2018) explores the impact that epistemology has for the implications of plagiarism in academic research. A number of authors consider the ethical responsibilities that health professionals may have as a result of knowledge, be it knowledge that a prescribed drug might be used to end a patient's life (Duckett 2018) or knowledge that a patient will be returned to a harmful environment after discharge (Essex and Isaacs 2018). Other articles discuss the obligation of professionals to have and use knowledge in particular contexts, including the importance of ethical awareness amongst research investigators in China (Zhang, Huang, and Chen 2018) and the need to incorporate ethical and legal knowledge as an integral component of clinical decision-making (Parker et al. 2018). The power and limits of information derived from clinical testing and the rights of (potential) parents to use this information is also a common thread. Manzini and Vears (2018) discuss the appropriateness of predictive psychiatric genetic testing in minors, while both Shahvisi (2018) and Smith and Taylor-Sands (2018) explore non-medical sex selection in the context of assisted reproductive technologies. Finally, Tamariz et al. (2018) discuss perspectives of research participants and the implications that health literacy and misunderstandings surrounding the therapeutic benefits of research participation may have on willingness of minorities to participate in research.

Another theme that runs broadly through much of the issue is how we respond to change-be it emerging technologies such as donor assisted conception, preimplantation sex selection, predictive psychiatric genetic testing, or vaccine pharmacotherapy, changes is how research is conducted including the shift to developing countries and the rise of participatory and participant-led research, or the ever-changing legal environment surrounding the beginning and end of life. Carfora et al. (2018) discuss the emerging interest in immune therapies to treat addictions, a novel approach that has the 
potential to generate profound ethical challenges around consent and integrity of the person (imagining, for instance, mandatory treatment requirements by courts as one future scenario to emerge from such scientific knowledge). The review of J. Benjamin Hurlbut's book Experiments in Democracy: Human Embryo Research and the Politics of Bioethics, by Giulia Cavaliere (2018), describes the historical debates in the Unite States about human embryo research, an example of ethics-rich change if ever there was one.

It is hard to maintain a dialectic or exchange in a quarterly journal, but we do so whenever possible, even after a considerable time lag from the original article in question. Quinones and colleagues (2018) make a Critical Response to Armus' article (2016) about the Pueyo tuberculosis vaccine incident in Argentina in the 1940s. They provide further evidence that the putative vaccine did not have scientific worth, appropriate scrutiny did not occur, and perverse commercial forces were in operation.

Causation is a complex area of philosophy and jurisprudence in general (see Frekelton and Mendelson 2002), but science and medicine tend to have a narrow forensic view of it. This is well seen in the consideration of death and dying. As a result of the (of course laudable and necessary) interdict on causing death in most of the major world religious traditions, all kinds of intellectual gymnastics are deployed to defend "non-causal" approaches in care and decision-making at the end of life. In the Christian tradition, the so-called "doctrine" of double effect is constantly invoked, and at times tortured, to preserve causal neutrality: that is to give a line of moral reasoning that removes human agency from the course of action in question. Peter Singer (1996) once described the sanctity of life as a "fig leaf" that ethics should discard. The doctrine, as applied to treatment abatement decisions and palliative care at the end of life, and indeed to assisted dying, often seems to be applied in this manner. Duckett (2018) discusses the use of the doctrine in a recent tribunal consideration of provision of a barbiturate to a person with a terminal illness. To argue that such provision is anything but providing the means of ending life seems both odd and unnecessary, and only really serves to show that assisted dying needs to be considered directly and unambiguously for what it is. The pathways to death have been remorselessly changing over the last half-century or so, with prolonged dying in old age (usually in the 75-85 years age range) over months and years from chronic diseases, including dementia in its various forms, now becoming the norm. Whilst modern palliative care can provide acceptable relief to most on these journeys, and is constantly improving its reach and capacity, there is still a need to recognize and respond to those situations where a person wishes to die at a time of their own choosing. Double effect cannot help us here because death is the desired outcome, and human agency (and causation) is most definitely invoked.

Continuing in this domain, in the Recent Developments feature, Bernadette Richards reports on the recent passage of legislation in the state of Victoria (Australia), that does indeed address causation directly, by permitting assisted dying, subject to stringent conditions and procedures (Richards and Coggon 2018). John Coggan reports how the law in England is dealing with the cessation of life-sustaining medical provision of hydration and alimentation to people with a type of severe irreversible brain damage, previously known as persistent vegetative state (now post coma unresponsive state). The requirement for all such cases to be referred to a court for a decision has now been removed (having been put in place in the landmark House of Lords Bland judgment of 1992), subject to a number of conditions. This may be seen as another slow step in dealing with the chronic "causal anxiety" that surrounds decisionmaking around death and dying, albeit for a small and highly specialized part of a much bigger picture.

\section{References}

Armus, D. 2016. On TB vaccines, patients' demands, and modern printed media in times of biomedical uncertainties: Buenos Aires, 1920-1950. Journal of Bioethical Inquiry 13(1): 35-45.

Borgan, S.F., J.Z. Amarin, A.K. Othman, H.H. Suradi, Y.Z. Qwaider. 2018. Truth disclosure practices of physicians in Jordan. Journal of Bioethical Inquiry 15(1). https://doi. org/10.1007/s11673-018-9837-x

Camporesi, S. 2018. Human embryos, genome editing, and noninvasive prenatal testing: some reflections on ethics and reproduction looking back at 2017 and ahead at 2018 . Journal of Bioethical Inquiry 15(1): https://doi.org/10.1007 /s11673-018-9840-2.

Carfora, A., P. Cassandro, A. Feola, F. La Sala, R. Petrella, and R. Borriello. 2018. Ethical implications in vaccine pharmacotherapy for treatment and prevention of drug of abuse dependence. Journal of Bioethical Inquiry 15(1). https://doi. org/10.1007/s11673-017-9834-5

Cavaliere, G. 2018. Disciplining bioethics: The debate over human embryo research. Review of J. Benjamin Hurlbut, 2017, Experiments in democracy: Human embryo research and the 
politics of bioethics, Columbia University Press (New York, 978-0-231-17954-6, 376 pp.). Journal of Bioethical Inquiry 15(1). https://doi.org/10.1007/s11673-017-9830-9

Duckett, S. 2018. Knowing, anticipating, even facilitating but still not intending: Another challenge to double effect reasoning. Journal of Bioethical Inquiry 15(1). https://doi.org/10.1007 /s11673-017-9827-4

Essex, R., and D. Isaacs. 2018. The ethics of discharging asylum seekers to harm: A case from Australia. Journal of Bioethical Inquiry 15(1). https://doi.org/10.1007/s11673-017-9833-6

Frekelton, I., and D. Mendelson (eds). 2002. Causation in law and medicine. Dartmouth: Ashgate.

Jacmon, H. 2018. Disclosure is inadequate as a solution to managing conflicts of interest in human research. Journal of Bioethical Inquiry 15(1). https://doi.org/10.1007/s11673017-9824-7

Lima, N.S. 2018. Narrative identity in third party reproduction: Normative aspects and ethical challenges. Journal of Bioethical Inquiry 15(1). https://doi.org/10.1007/s11673017-9823-8

Magee, B. 1997. Confessions of a philosopher. London: Weidenfeld \& Nicolson.

Manzini, A., and D. Vears. 2018. Predictive psychiatric genetic testing in minors: An exploration of the non-medical benefits. Journal of Bioethical Inquiry 15(1). https://doi.org/10.1007 /s11673-017-9828-3

Parker, M., L. Willmott, B. White, G. Williams, and C. Cartwright. 2018. Law as clinical evidence: A new constitutive model of medical education and decision-making. Journal of Bioethical Inquiry 15(1). https://doi.org/10.1007/s11673017-9836-3

Penders, B. 2018. Beyond trust: Plagiarism and truth. Journal of Bioethical Inquiry 15(1). https://doi.org/10.1007/s11673017-9825-6
Quiñones, E.B., L. Goldin, I.M.I. Bignone, and R.A. Diez. 2018. A critical view of “On TB vaccines, patients' demands, and modern printed media in times of biomedical uncertainties: Buenos Aires, 1920-1950". Journal of Bioethical Inquiry 15(1). https://doi.org/10.1007/s11673-017-9832-7

Richards, B., and J. Coggon. 2018. Assisted dying in Australia and limiting court involvement in withdrawal of nutrition and hydration. Journal of Bioethical Inquiry 15(1). https://doi. org/10.1007/s11673-018-9839-8

Shahvisi, A. 2018. Engendering harm: A critique of sex selection for "family balancing". Journal of Bioethical Inquiry 15(1). https://doi.org/10.1007/s11673-017-9835-4

Shaw, D. 2018. Protecting participants in thought experiments: The role of the research ethics committee. Journal of Bioethical Inquiry 15(1). https://doi.org/10.1007/s11673017-9831-8

Singer P. 1996. Rethinking life and death. St Martin's Press.

Smith, M.K., and M. Taylor-Sands. 2018. Comparing non-medical sex selection and saviour sibling selection in the case of JS and LS v Patient Review Panel: Beyond the welfare of the child? Journal of Bioethical Inquiry 15(1). https://doi. org/10.1007/s11673-018-9838-9

Soofi, H. 2018. Mode 2 knowledge production in the context of medical research: A call for further clarifications. Journal of Bioethical Inquiry 15(1). https://doi.org/10.1007/s11673017-9822-9

Tamariz, L., I. Kirolos, F. Pendola, E.N. Marcus, O. Carrasquillo, J. Rivadeneira, and A. Palacio. 2018. Minority veterans are more willing to participate in complex studies compared to non-minorities. Journal of Bioethical Inquiry 15(1). https://doi.org/10.1007/s11673-017-9829-2

Zhang, L., X.X. Huang, and H.F. Chen. 2018. An exploration of the protective effects of investigators' ethical awareness upon subjects of drug clinical trials in China. Journal of Bioethical Inquiry 15(1). https://doi.org/10.1007/s11673-017-9826-5 